\title{
Paradigm Shift of Tourist Behavior in Eurasian Countries under Pandemic Conditions
}

\author{
Asst. Prof. Dr. Ayça Oralkan (Beykent University, Turkey)
}

\begin{abstract}
Tourism has become a dynamic economic resource for Eurasian countries in recent decades, providing wellbeing for the people living in the destinations. The pandemic has forced societies to adapt to the constraints it imposes due to significant socioeconomic effects. Because of the fact that the tourist behavior and social life in the destinations are significantly affected by pandemic conditions, the countries are developing strategies to overcome the safety concerns with reconstructed travel and tourism norms. Due to the nature of the process, the main source of the competitive environment of the tourism sector is tourist behavior, and one of the primary criteria of potential tourists in their destination selection is security risk assessments. With the constraints shaped under pandemic conditions, a dramatic decrease has been observed in the intensity of tourism activities on a global basis. Yet, tourism is recognized as one of the most dynamic and fast-growing sectors worldwide with a positive welfare effect on the people living in the destinations. Therefore, there is a strong intention to develop favorable conditions, including innovative solutions, to meet tourist motivations. The aim of this paper is to develop theoretical approaches to evaluate the potential tourist behavior regarding Eurasian Countries under the constraints of the pandemic.
\end{abstract}

\section{Introduction}

Tourism has become one of the world's main economic sectors through its contribution to income and employment. Besides, for decades, tourism has provided well-being for the people in the destinations. On the other hand, COVID-19 continues to negatively impact travel due to the restrictions that governments have been compelled to enforce. With the travel restrictions caused by the pandemic conditions and the shocking effects of economic uncertainties, Eurasian tourism is far below the usual statistics. Due to tourism's need for ease of travel, possible travel restrictions have compelling negative effects on the tourism sector. The Covid-19 pandemic, which has gained a global dimension, also causes reservations due to economic recession, apart from security concerns (Yeh, 2020). It is difficult to make general assessments about the process, as the negative effects of the pandemic conditions have not yet ended. However, for the long-term efficiency of tourism components, conditions need to be built to ensure that the people living in destinations have at least an acceptable level of living standards. In this context, it has been repeatedly experienced on a country basis that security concerns can greatly affect tourism demand. Apart from the uncertainties in the mandatory practices that restrict life strategies in attraction centers, states can take inclusive measures, even including the closing of borders. On the other hand, when there are signs that the transmission rate is under control during the pandemic process, governments are determining strategies that include flexibility in order to reactivate tourism, which has an important share in state economies. However, in this current period of uncertainties, one of the primary factors determining consumer behavior has been the perception of risk. It is obvious that in order to meet the new expectations that have become evident with this change in the behavior of the tourist candidates, new structures that can ensure the formation of new standards must be realized. In the light of economic evaluations, it is predicted that tourism and tourism-related businesses will be among the most adversely affected sectors, while the greater the share of the tourism sector in the economy of that country, the greater the impact of the pandemic will naturally be (Khalid et al., 2021). Innovative approaches, which become evident with the transition from over-tourism complaints to tourism absence concerns caused by pandemic conditions, focus on models that are compatible with sustainable tourism parameters. The aim of this paper is to develop theoretical approaches to evaluate the potential tourist behavior regarding Eurasian Countries under the constraints of the pandemic.

\section{Background}

Due to the global spread of COVID-19, which causes significant health problems with a high rate of transmission, the World Health Organization first declared a worldwide emergency and quite soon after (on March 11, 2020), announced that this threat is a pandemic (Williams, 2020). Due to the fact that city centers are much busier than in the past with the advantage of diversity and convenience in transportation, it is possible for a single passenger to infect different parts of the world in a very short time (Hall et al., 2020). The pandemic, which has affected all areas of life, has deeply affected especially the tourism industry on a global scale (Anower et al., 2020). After the health-related crises such as SARS, bird flu, and swine flu, which have been seen to affect tourism negatively, Covid-19 has had very serious effects on the global scale, especially in the travel and tourism sector (Bas \& Sivaprasad, 2020). It is seen that the tourism sector is considered in the priority category in terms of both its share in the economies of the countries and the welfare of the people living in the destinations in this challenging process where governments try to allocate a balance between the need to take the necessary resistance measures 
against pandemic conditions and the need to protect the lower limits in economic parameters (Higgins, 2020). Indeed, the perception of risk due to health concerns in destinations has become commonplace, especially in cases of the presence of disease-carrying insects such as ticks or low hygiene standards, especially in attraction center preferences made on the basis of natural attractions (Zenker et al., 2021). However, in pandemic conditions, which can be examined from individual and social perspectives in general risk assessments, there is a tendency to decrease in the demand for tourism centers that are relatively more affected (Qiu et al., 2020).

\section{Main Focus of the Paper}

Tourism is accepted as one of the most critical sectors on the international ground with its contribution to the state budget and its significant effect on the well-being of the people living in the tourism centers. Although the constraints shaped by the pandemic conditions have been daunting for tourism, a dynamic adaptation process in which paradigms change is taking place with the support of technological infrastructure and compatible marketing strategies. This paper aims to address the adaptation process in tourism, which tends to work despite all these negativities and possible marketing strategies that have the potential to be compatible with changing paradigms.

\section{From Mass Tourism to Sustainable Tourism}

The tourism industry, whose share in the country's income reaches indispensable levels, provides development and employment in Eurasian countries and contributes to the living standards of the people of the region in the destinations. With travel restrictions coming with the pandemic, better quality tourism models aiming for longer stays, which offer higher spending opportunities, have started to be preferred instead of models that try to reach more tourists (Benjamin et al., 2020). Rather than returning to the pre-pandemic tourism understanding, a strong motivation is expected to move towards the more appropriate one. In addition to the positive contributions of tourism to the welfare of the region, it is obvious that it can cause problems in infrastructure and environmental issues. Mass tourism, which can have negative effects on infrastructure and the environment, has had to go to the level of stagnation due to the restrictions caused by the pandemic (Koh, 2020). On the other hand, one of the priority conditions of sustainable tourism is that the people of the region in the destinations have suitable living standards (Andereck et al., 2007). While tourism brought prosperity to the region with the job opportunities it provided, the negative conditions brought by mass tourism were emphasized globally before the pandemic. That is, over-tourism had the potential and tendency to cause problems upon nature, environment, and social life in the destinations. Besides, for sustainable tourism, strategies shaped with an economic perspective should also include solutions to protect nature and the environment. Sustainable tourism includes not only the infrastructure and environmental components or economic parameters but also the social dimension, which includes the interaction between tourists and the people of the destination (Kristiana et al., 2021). In this context, responsible tourism refers to the effort to reduce the possibility of negative impacts on destinations and increase benefits for the region (Caruana et al., 2014).

\section{Innovative Approaches for Tourism Components}

In today's pandemic conditions, a global perception of social innovation, which has the potential to be triggered by consumer behavior and can be supported by destination marketing strategies, can contribute to the dominance of infrastructure and environment-friendly tourism approach. Mainly due to the global economic impact of tourism and its positive contribution to life in touristic regions, it is observed that when the number of coronavirus cases is reduced to acceptable levels, governments stretch the restrictions and avoid statements that increase the perception of risk. Nevertheless, it is observed that one of the most critical components of marketing strategies is reliability under social life conditions shaped by pandemic restrictions. For example, in order to meet the minimum Covid19 risk expectation that is evident in tourist candidates under pandemic conditions, hotels take measures that ensure social distance and reduce face-to-face interaction with staff (Shin \& Kang, 2020). Besides, hotels can develop voice-controlled solutions instead of remote controls for air conditioners and televisions, or smartphone applications can be used to perform functions in smart rooms.

Among the methods of re-developing tourism after the pandemic, there are virtual reality applications, which have become evident by making use of today's technology in marketing strategies created to attract the attention of potential tourist candidates (Yung et al., 2021). Pandemic-safety parameters have been the ones that preclude features such as sun-sand tourism, which have a high attraction, and even those that may tend to prolong the total stay of tourists with their unique cultural values. Heritage attraction, which increases the demand of tourist candidates for destinations and contributes to the prolongation of their stay, is an important tourism component (Lin et al., 2020). Similarly, creative tourism can contribute to the provision of more impressive service opportunities to potential tourist candidates in attractions. The effects of the level of satisfaction with the touristic experience can continue to exist after the trip, and the effects of the retrospective analysis carried out with the memories gained can last much longer than the trip itself (Godovykh \& Tasci). In this context -with its quality- 
enhancing effect- creative tourism, which leads to improvements in social life through tourism components, also contributes to local economies (Chang et al., 2014).

\section{Quantum Tunneling Analogy on the Main Topic}

Quantum tunneling is the state of being able to cross a barrier with a greater potential compared to the energy possessed by any particle and this situation, which violates the principles of classical mechanics, has the potential to answer many scientific questions such as fusion reaction conditions in the Sun (Trixler, 2013). In order to make the analogy easier to understand, quantum tunneling can be exemplified by adapting it to the visible scale. Whether a basketball rolling on flat ground can cross the hill or not is determined by whether that basketball has the necessary energy. In classical mechanics, if there is enough energy in the basketball, it will go over the hill, if not, it will turn back on its way up and roll in the opposite direction. The probability of crossing the hill, which requires more energy than it has, is seen as 0 in classical mechanics; that is, being on the other side of the hill is considered forbidden in the principles of classical mechanics. On the other hand, in Quantum mechanics, the basketball has a wave characteristic and the probability of appearing on the other side of the hill is possible if the wave distribution exceeds the hill.

Tourism has become a significant economic source for the countries and generates well-being for the people living in the destinations. In this manner, tourism centers push the limits of constraints with the effort of adaptation and develop marketing strategies compatible with the pandemic conditions. In addition, it is seen that there are travel motivations for tourist candidates that have been internalized for decades. This mutual demand increases the number of attempts so much that tourism somehow finds a way despite all the restrictions that the states have updated. Despite the restrictions shaped by the pandemic conditions, it has been seen how resilient the motivation that ensures the continuation of tourism is. Under normal conditions, any touristic trip potential can be expressed by whether the motivation of the tourist candidate can meet the cost and risk perception. Despite the economic uncertainty felt globally in the pandemic conditions and the risk perception increasing in parallel with the rate of contamination, it is observed that tourism motivation has a high level of resistance with its nature pushing the limits.

\section{Changing Paradigms}

Among the factors affecting the change in paradigms, the potential for further growth in the tourism sector, increasing competition on a global scale, the increasing expectations of tourists with their increasing experience, awareness of the negative effects of over-tourism -especially on infrastructure, environment, and local living conditions- and the approaches formed within the scope of sustainable tourism proposals from many institutions and organizations around the world, can be counted (Peeters et al., 2018). Under the conditions of the pandemic, immense fluctuations took place, especially in these processes, which have significant potential for change in tourist behavior paradigms. In parallel with the measures and restrictions taken during the pandemic conditions, there have been significant changes in social life, such as the focus on remote working (George et al., 2020). Adaptation efforts in many different sectors have gained momentum with the contribution of technological infrastructure enhancement. In a period when the security sensitivity is so high, it is observed that tourist candidates have priority expectations for security-related issues, both for the public and the tourists at the attraction centers. With the impact of the pandemic, it has been seen how the perception of trust has a decisive role for tourism and how resistant the motivation for the continuity of tourism is despite the relevant restrictions brought by the countries. Since there may be changes in the distribution of demand for tourism centers due to many active components, it is necessary to evaluate the current destination suggestions in order to follow the general satisfaction of the tourists (Yang et al., 2017). Under normal circumstances, the ongoing stages of tourist behavior such as the formation of tourism expectations, collection of information about possible options, and examination of tourist comments can be mentioned. However, it is expected that the intense sharing about the pandemic on social networking platforms will affect the approaches of the tourist candidates in the decision stages (Wachyuni \& Kusumaningrum, 2020). It is observed that the risk perception of pandemic security in that destination is one of the determining criteria in the general satisfaction assessments of tourist travels in the choices determined as trust priority under pandemic conditions. This fluctuation in paradigms strengthens the expectation to take measures against the problems caused by over-tourism. In order to reduce the negative effects of over-tourism after the pandemic and to gain continuity in the long term, it would be appropriate to set new precautionary standards under the umbrella of sustainable tourism. When the environmental change factors are examined, it is seen that the reason is not only related to the adaptation to ecological balances but also human-induced, especially due to excessive consumption of natural resources and inappropriate wastes of production (Hall, 2010). For example, prices may be increased in the context of the decrease in the number of tourists due to travel restrictions. While potential problems related to infrastructure and the environment due to over-tourism can be brought under control with the decrease in the number of tourists, the increase in the standards in tourism components can be pleasing for both tourists and the local people. 


\section{Tourism Marketing under the Pandemic}

The performance of tourism centers to provide services at appropriate standards, especially in peak seasons, has always had the potential to be a determining criterion for tourist candidates at the decision stage. With the contribution of tourism to the global economy in recent decades, the importance of marketing strategies that enable destinations to gain an advantageous position in international competition has increased to a great extent. On the other hand, with the pandemic, it has become much more critical that transportation and accommodation conditions are compatible with popular measures. Destination branding, which includes components such as destination image structuring in addition to destination marketing, prioritizes the reputation of the touristic center (Ruiz-Real et al., 2020). In this manner, even the long-term strategies are seen as focused on adaptation to pandemic conditions. The interactions between potential tourists and touristic centers, which have become more effective with the use of social networks and smartphones, play an important role in the positive evaluation of destinations (Chen et al., 2020). With all these communication and interaction possibilities, in pandemic conditions, it is necessary to emphasize the measures taken within the scope of the pandemic in the effective marketing strategies necessary for the long-term sustainability of tourism. As in the general case of crises -in the case of acting with awareness- the conditions can be turned into opportunities and new norms and standards can be determined for tourism to be more sustainable (Varzaru et al., 2021). In order for impressive information about a particular attraction center to reach the tourist candidates, first of all, a sense of trust must be allocated. If the set of measures placed in the focus of sensitivity in pandemic conditions is not found sufficient or realistic by potential tourists, it may adversely affect the demand for that region.

\section{Future Research Directions}

In the tourism sector, it is seen that the changing paradigms with strategies aimed at eliminating the security concern in the context of pandemic conditions provide an advantage in terms of sustainability, especially in infrastructure and environmental issues. Although tourism has become an important source of the national economy with the job opportunities and living standards it provides in the region, the negative conditions brought by mass tourism continue to be emphasized. On the other hand, the priority given to mass tourism in sectorial investments for decades will cause it to tend to the pre-pandemic situation instead of the appropriate one after the pandemic. It is seen that in the destination marketing strategies shaped by the decrease in the number of international tourist candidates due to the security sensitivity in the pandemic conditions, better quality service and longer stay period are aimed. It can be expected that this situation will contribute to the sustainability of tourism if possible new standards related to infrastructure and environment are introduced. New criteria that can be determined within the scope of infrastructure and environmental standards in tourism centers in the short and long term may be the subject of future research.

\section{Conclusion}

Destination promotions emphasizing innovative approaches within the scope of pandemic measures contribute to shaping a positive impression. Advertisements that emphasize compliance with pandemic measures especially in travel, accommodation conditions, and regional evaluations provide an advantage in international competition for tourism centers. It is aimed to overcome the security concerns through the travel and tourism components organized with the effort to build a positive image for the projection of the social life in the destinations that have deeply been affected by the pandemic conditions. Instead of returning to the pre-pandemic tourism strategies, it seems that it may be possible to turn into an opportunity to build more compatible options for infrastructure and the environment. Perceived security in tourist destinations is a critical factor in potential tourists' decisions, and a possible sense of distrust can have a lasting negative impact. The perception of security, which has become one of the priority criteria in destination selection especially during the pandemic period, requires innovative measures to be taken in line with the necessary measures and emphasizing these solutions in marketing strategies.

\section{References}

- $\quad$ Andereck, K. L., Valentine, K. M., Vogt, C. A., \& Knopf, R. C. (2007). A Cross-Cultural Analysis of Tourism and Quality of Life Perceptions. Journal of Sustainable Tourism, 15(5), 483-502. https://doi.org/10.2167/jost612.0

- $\quad$ Anowar, M., Bhuiyan, H., Hassan, S., Darda, A., \& Habib, M. W. (2020). Aspects of Sustainable Tourism Development and COVID-19 Pandemic. Preprints, August. www.preprints.org

- Bas, T., \& Sivaprasad, S. (2020). The Impact of the COVID-19 Pandemic Crisis on the Travel and Tourism Sector: UK Evidence. SSRN Electronic Journal. https://doi.org/10.2139/ssrn.3623404

- Benjamin, S., Dillette, A., \& Alderman, D. H. (2020). "We Can't Return to Normal”: Committing to Tourism Equity in the Post-pandemic age. Tourism Geographies, 22(3), 476-483. https://doi.org/10.1080/14616688.2020.1759130 
- Caruana, R., Glozer, S., Crane, A., \& McCabe, S. (2014). Tourists' Accounts of Responsible Tourism. Annals of Tourism Research, 46, 115-129. https://doi.org/10.1016/j.annals.2014.03.006

- Chang, L. L., Backman, K. F., \& Huang, Y. C. (2014). Creative Tourism: A Preliminary Examination of Creative Tourists' Motivation, Experience, Perceived Value and Revisit Intention. International Journal of Culture, Tourism, and Hospitality Research, 8(4), 401-419. https://doi.org/10.1108/IJCTHR-04-2014-0032

- Chen, R., Zhou, Z., Zhan, G., \& Zhou, N. (2020). The Impact Of Destination Brand Authenticity And Destination Brand Self-Congruence On Tourist Loyalty: The Mediating Role Of Destination Brand Engagement. Journal of Destination Marketing and Management, 15(3688), 100402. https://doi.org/10.1016/j.jdmm.2019.100402

- George, G., Lakhani, K. R., \& Puranam, P. (2020). What has changed? The Impact of Covid Pandemic on the Technology and Innovation Management Research Agenda. Journal of Management Studies, 1-5. https://doi.org/10.1111/joms. 12634

- Godovykh, M., \& Tasci, A. D. A. (2021). The Influence of Post-Visit Emotions on Destination Loyalty. Tourism Review, 76(1), 277-288. https://doi.org/10.1108/TR-01-2020-0025

- Hall, C. M. (2010). Changing Paradigms and Global Change: From Sustainable to Steady-State Tourism. Tourism Recreation Research, 35(2), 131-143. https://doi.org/10.1080/02508281.2010.11081629

- Hall, C. M., Scott, D., \& Gössling, S. (2020). Pandemics, Transformations and Tourism: Be Careful What You Wish for. Tourism Geographies, 22(3), 577-598. https://doi.org/10.1080/14616688.2020.1759131

- Higgins-Desbiolles, F. (2020). Socialising Tourism for Social And Ecological Justice After Covid-19. Tourism Geographies, 22(3), 610-623. https://doi.org/10.1080/14616688.2020.1757748

- $\quad$ Khalid, U., Okafor, L. E., \& Burzynska, K. (2021). Does the size of the tourism sector influence the economic policy response to the COVID-19 pandemic? Current Issues in Tourism, 1-20. https://doi.org/10.1080/13683500.2021.1874311

- Koh, E. (2020). The end of Over-Tourism? Opportunities in a Post-Covid-19 World. International Journal of Tourism Cities. https://doi.org/10.1108/ijtc-04-2020-0080

- $\quad$ Kristiana, Y., Pramono, R., \& Brian, R. (2021). Adaptation Strategy of Tourism Industry Stakeholders During the COVID-19 Pandemic: A Case Study in Indonesia. Journal of Asian Finance, Economics and Business, 8(4), 0213-0223. https://doi.org/10.13106/jafeb.2021.vol8.no4.0213

- $\quad$ Lin, L. P. (Lynn), Huang, S. C. (Lucy), \& Ho, Y. C. (2020). Could Virtual Reality Effectively Market Slow Travel in a Heritage Destination? Tourism Management, 78(104027). https://doi.org/10.1016/j.tourman.2019.104027

- $\quad$ Qiu, R. T. R., Park, J., Li, S. N., \& Song, H. (2020). Social Costs of Tourism During The Covid-19 Pandemic. Annals of Tourism Research, 84. https://doi.org/10.1016/j.annals.2020.102994

- Peeters, P., Gössling, S., Klijs, J., Milano, C., Novelli, M., Dijkmans, C., Eijgelaar, E., Hartman, S., Heslinga, J., Isaac, R., Mitas, O., Moretti, S., Nawijn, J., Papp, B., \& Postma, A. (2018). Research for TRAN Committee-Overtourism: Impact and Possible Policy Responses. Research for TRAN CommitteeOvertourism: Impact and Possible Policy Responses, October, 1-255. http://www.europarl.europa.eu/thinktank/en/document.html?reference=IPOL_STU(2018)629184

- $\quad$ Ruiz-Real, J. L., Uribe-Toril, J., \& Gázquez-Abad, J. C. (2020). Destination Branding: Opportunities And New Challenges. Journal of Destination Marketing and Management, 17(100453). https://doi.org/10.1016/j.jdmm.2020.100453

- Shin, H., \& Kang, J. (2020). Reducing Perceived Health Risk to Attract Hotel Customers in The Covid-19 Pandemic Era: Focused on Technology Innovation for Social Distancing and Cleanliness. International Journal of Hospitality Management, 91(102664), 1-9. https://doi.org/10.1016/j.ijhm.2020.102664

- Trixler, F. (2013). Quantum Tunnelling to the Origin and Evolution of Life. Current Organic Chemistry, 17(16), 1758-1770. https://doi.org/10.2174/13852728113179990083

- Vărzaru, A. A., Bocean, C. G., \& Cazacu, M. (2021). Rethinking Tourism Industry in Pandemic COVID-19 Period. Sustainability, 13(12), 6956. https://doi.org/10.3390/su13126956

- Wachyuni, S. S., \& Kusumaningrum, D. A. (2020). The Effect of COVID-19 Pandemic: How are the Future Tourist Behavior? Journal of Education, Society and Behavioural Science, 33(4), 67-76. https://doi.org/10.9734/jesbs/2020/v33i430219

- Williams, C. C. (2020). Impacts of the Coronavirus Pandemic on Europe's Tourism Industry: Addressing Tourism Enterprises and Workers in the Undeclared Economy. International Journal of Tourism Research, 1(10), 1-10. https://doi.org/10.1002/jtr.2395 
- $\quad$ Yang, L., Wu, L., Liu, Y., \& Kang, C. (2017). Quantifying Tourist Behavior Patterns by Travel Motifs and Geo-Tagged Photos from Flickr. ISPRS International Journal of Geo-Information, 6(11), 1-18. https://doi.org/10.3390/ijgi6110345

- Yeh, S. S. (2021). Tourism Recovery Strategy Against Covid-19 Pandemic. Tourism Recreation Research, 46(2), 188-194. https://doi.org/10.1080/02508281.2020.1805933

- $\quad$ Yung, R., Khoo-Lattimore, C., \& Potter, L. E. (2021). Virtual Reality and Tourism Marketing: Conceptualizing a Framework on Presence, Emotion, And Intention. Current Issues in Tourism, 24(11), 1505-1525. https://doi.org/10.1080/13683500.2020.1820454

- Zenker, S., Braun, E., \& Gyimóthy, S. (2021). Too afraid to Travel? Development of a Pandemic (COVID19) Anxiety Travel Scale (PATS). Tourism Management, 84(January), 1-11. https://doi.org/10.1016/j.tourman.2021.104286 